Prot ect i ve effects of sodi um thi osul fat e for ci spl at i n- medi at ed ot oxi ci ty i $n$ pat i ent s wi th head and neck cancer

\begin{tabular}{|l|l|}
\hline 著者 & 石川 絵里子 \\
\hline 著者別表示 & I shi kawa Er i ko \\
\hline $\begin{array}{l}\text { j our nal or } \\
\text { publ i cat i on t i t l e }\end{array}$ & 博士論文本文Ful I \\
\hline 学位授与番号 & 13301甲第4435号 \\
\hline 学位名 & 博士 (医学) \\
\hline 学位授与年月日 & 2016- 06- 30 \\
\hline URL & $\mathrm{ht} \mathrm{t} \mathrm{p:} \mathrm{//hdl} \mathrm{.} \mathrm{handl} \mathrm{e.} \mathrm{net} \mathrm{/2297/46445}$ \\
\hline
\end{tabular}




\section{Protective effects of sodium thiosulfate for cisplatin-mediated ototoxicity in patients with head and neck cancer}

Eriko Ishikawa, Hisashi Sugimoto, Miyako Hatano, Yosuke Nakanishi, Akira Tsuji, Kazuhira Endo, Satoru Kondo, Naohiro Wakisaka, Shigeyuki Murono, Makoto Ito \& Tomokazu Yoshizaki

To cite this article: Eriko Ishikawa, Hisashi Sugimoto, Miyako Hatano, Yosuke Nakanishi, Akira Tsuji, Kazuhira Endo, Satoru Kondo, Naohiro Wakisaka, Shigeyuki Murono, Makoto Ito \& Tomokazu Yoshizaki (2015) Protective effects of sodium thiosulfate for cisplatin-mediated ototoxicity in patients with head and neck cancer, Acta Oto-Laryngologica, 135:9, 919-924, DOI: 10.3109/00016489.2015.1035797

To link to this article: http://dx.doi.org/10.3109/00016489.2015.1035797

曲 Published online: 10 Apr 2015.

Submit your article to this journal $₫$

Џ Article views: 206

View related articles $\smile$

View Crossmark data $\nearrow$ 


\title{
Protective effects of sodium thiosulfate for cisplatin-mediated ototoxicity in patients with head and neck cancer
}

\author{
ERIKO ISHIKAWA ${ }^{1}$, HISASHI SUGIMOTO ${ }^{2}$, MIYAKO HATANO $^{2}$, YOSUKE NAKANISHI $^{2}$, \\ AKIRA TSUI ${ }^{2}$, KAZUHIRA ENDO ${ }^{2}$, SATORU KONDO ${ }^{2}$, NAOHIRO WAKISAKA ${ }^{2}$, \\ SHIGEYUKI MURONO ${ }^{2}$, MAKOTO ITO $^{3} \&$ TOMOKAZU YOSHIZAKI $^{2}$ \\ ${ }^{1}$ Otolaryngology-Head and Neck Surgery, Toyama Prefectural Hospital, Toyama, ${ }^{2}$ Department of Otolaryngology-Head \\ and Neck Surgery, Kanazawa University Graduate School of Medical Science, Kanazawa and ${ }^{3}$ Pediatric \\ Otolaryngology, Fichi Children's Medical Center Tochigi, Fichi Medical University, Shimotsuke, fapan
}

\begin{abstract}
Conclusions: Intra-arterial high-dose cisplatin chemoradiation (CRT-IA) with sodium thiosulfate (STS) causes relatively less severe cisplatin ototoxicity than intravenous cisplatin chemoradiation without STS (CRT-IV). The results of this study also suggest that early detection of ototoxicity is possible by testing the hearing loss at ultra-high frequencies. Objectives: To investigate protective effects of STS against cisplatin ototoxicity. Methods: Between 2011 and 2013, 18 patients with head and neck carcinomas were treated with intra-arterial infusions of high-dose cisplatin (range 100-180 mg/body, mean $111 \mathrm{mg} / \mathrm{body}$; range 2-5 courses, mean 3.6 courses) and systemic administration of cisplatin (range $66-185 \mathrm{mg} / \mathrm{body}$, mean $130 \mathrm{mg} / \mathrm{body}$; range 1-3 courses, mean 2.6 courses) and concurrent radiation therapy (range 60-70 Gy, mean 69 Gy). Cisplatin was neutralized by STS in CRT-IA but not in CRT-IV. Results: Intra-arterial infusion in the high-dose cisplatin group caused significant hearing loss at ultra-high frequencies of 10 and $12 \mathrm{kHz}(p=0.028,0.039$, respectively), whereas the group receiving systemic administration of cisplatin had significant hearing loss at high frequencies of 8 and $10 \mathrm{kHz}(p=0.016,0.027$, respectively).
\end{abstract}

Keywords: Cisplatin, head and neck squamous cell carcinoma, chemoradiation, intra-arterial high-dose cisplatin

\section{Introduction}

Head and neck squamous cell carcinoma (HNSCC) is the sixth most common cancer worldwide [1]. Although HNSCC has a good prognosis after surgical therapy or irradiation in the early stages, advanced HNSCC has a poor prognosis. Cisplatin is a potent radiosensitizer, and is widely accepted as the standard of care in combined chemoradiotherapy in HNSCC $[2,3]$. The concurrent use of cisplatinbased chemotherapy with radiotherapy has been shown to improve the response rates. It also facilitates organ preservation in patients with advanced HNSCC.
Cisplatin induces monoadducts at nucleophilic sites and can subsequently lead to intrastrand and interstrand cross links in DNA. Once formed, these lesions can trigger apoptotic cascades, predominantly via the mitochondrial pathway. Similar events are observed in non-cancer cells [4]. The dose of cisplatin is an important determinant of the extent of cytotoxicity. To increase drug doses in the tumor while maintaining minimal systemic toxicity and overcoming the chemoradioresistance of a tumor, supradose cisplatin infusion via superselective intra-arterial chemotherapy was designed. This was achieved by using microcatheters placed angiographically to permit superselective rapid infusions while sodium

Correspondence: Tomokazu Yoshizaki, Department of Otolaryngology-Head and Neck Surgery, Kanazawa University Graduate School of Medical Science,
Kanazawa. E-mail: tomoy@med.kanazawa-u.ac.jp

(Received 27 February 2015; accepted 16 March 2015)

ISSN 0001-6489 print/ISSN 1651-2251 online (c) 2015 Informa Healthcare

DOI: $10.3109 / 00016489.2015 .1035797$ 
thiosulfate (STS) is systemically infused to protect against cisplatin toxicity.

The significant results of radiotherapy and concomitant intra-arterial cisplatin (RADPLAT), a concurrent supradose intra-arterial infusion of cisplatin (150 $\mathrm{mg} / \mathrm{m}^{2}$, four courses) with radiotherapy used against advanced HNSCC, were first reported by Robbins et al. in 1994 [5]. The systemic toxicity of RADPLAT is less severe than that of standard systemic chemotherapy protocols $[5,6]$. Previously, we reported the efficacy of our modified protocol of RADPLAT, termed the Kanazawa regimen (cisplatin 150 or $100 \mathrm{mg} /$ body intra-arterially (IA) and STS $14 \mathrm{~g} / \mathrm{m}^{2}$ intravenously (IV), two to three courses, radiotherapy $2 \mathrm{~Gy} /$ fraction, $66 \mathrm{~Gy})$. To increase the completion rate of the regimen, our protocol treated patients with a cisplatin dose lower than that used in the RADPLAT protocol. The feasibility of our protocol was better than that of RADPLAT. Moreover, the overall, local disease-free, and progression-free survival rates did not show significant differences despite the reduced doses and frequencies.

We have formulated a treatment using the Kanazawa regimen, and have assessed nephrotoxicity, hematologic toxicity, and mucosal events in detail. However, we have not evaluated ototoxicity in this regimen. In the present study, we compared the incidence of hearing loss in patients treated with the Kanazawa regimen and intravenous cisplatin chemoradiation without STS. We also compared the extent of cisplatin ototoxicity due to the Kanazawa regimen with that caused by RADPLAT [7].

\section{Material and methods}

\section{Patients and treatment}

Between 2011 and 2013, 18 patients with HNSCC were treated with intra-arterial infusion of high-dose cisplatin (range 100-180 mg/body, mean $111 \mathrm{mg} /$ body, range $2-5$ courses, mean 3.6 courses) or systemic administration of cisplatin (range $66-185 \mathrm{mg} /$ body, mean $130 \mathrm{mg} / \mathrm{body}$, range 1-3 courses, mean 2.6 courses) with concurrent radiation therapy (range 60-70 Gy, mean $69 \mathrm{~Gy})$. STS $\left(14 \mathrm{~g} / \mathrm{m}^{2} / 4 \mathrm{~h}\right)$ was simultaneously administered IV for cisplatin neutralization. All patients signed an informed consent. Group 1 (intra-arterial infusion of high-dose cisplatin) consisted of seven patients (all males). Group 2 (systemic administration of cisplatin) comprised 11 patients (9 males and 2 females). All patients received radiation treatment. Two patients had distant metastasis. Patients with ear pathology, history of acoustic/noise exposure, trauma, history of middle and inner ear surgery, and those who were taking any ototoxic drugs were excluded from the study. All included patients gave a detailed medical history and underwent clinical and hearing examination in addition to blood and urine analyses.

\section{Audiologic assessment}

Before the start of chemotherapy, baseline hearing threshold data (up to $12 \mathrm{kHz}$ ) were obtained by a pure-tone audiometer installed in a sound-proof room in the otolaryngology department. Air conduction (AC) thresholds were measured at frequencies of $0.125,0.25,0.5,1,2,4,8,10$, and $12 \mathrm{kHz}$; bone conduction (BC) thresholds were measured at $0.5,1$, 2 , and $4 \mathrm{kHz}$. Patients were reassessed 1-3 weeks after the last cisplatin infusion. The frequency spectrum of hearing loss was recorded for each subject.

\section{Statistical methods}

The data were analyzed using SPSS version 19. The Mann-Whitney U test was performed to compare the hearing abilities between the patients administered intra-arterial infusion of high-dose cisplatin and those given systemic administration of cisplatin. Ototoxicity was defined as hearing loss of $20 \mathrm{~dB}$ at one frequency. After chemotherapy, an increase of $20 \mathrm{~dB}$ above the baseline hearing threshold for an individual frequency was considered significant. During baseline audiometry, a frequency with an absent response was excluded from the observations.

\section{Results}

In this study, the patient age ranged from 45 to 82 years, with a majority aged $50-60$ years. The mean age of presentation was 63 years. The male to female ratio was $8: 1$ (Table I). The hearing levels were worsened by a statistically significant margin after chemotherapy at ultra-high frequencies of 8 , 10 , and $12 \mathrm{kHz}(p=0.012,0.002,0.011$, respectively, Wilcoxon signed rank test). The threshold shifts at low and high frequencies $(0.125-4 \mathrm{kHz})$ were not observed after therapy (Figure 1). During follow-up visits, two patients presented with subjective hearing loss and tinnitus at the first follow-up. Both of them were from group 2 (a 69-year-old male and a 56-yearold male). There was no statistical correlation between age and dose of cisplatin. There was no subjective or objective vertigo in any patient. Patients in group 1 had a mean age of 67 years and were treated with intra-arterial infusions of high-dose cisplatin. In this group, they had significant hearing loss according to the Wilcoxon signed rank test scale, and this loss was observed at ultra-high frequencies of 
Table I. Characteristics of patients $(n=18)$ and treatment.

\begin{tabular}{|c|c|c|c|}
\hline Characteristic & Group 1 & Group 2 & Entire study group \\
\hline \multicolumn{4}{|l|}{ Age (years) } \\
\hline Median & 67 & 61 & 63 \\
\hline Range & $57-82$ & $45-72$ & $45-82$ \\
\hline \multicolumn{4}{|l|}{$\operatorname{Sex}(n)$} \\
\hline Male & 7 & 9 & 16 \\
\hline Female & 0 & 2 & 2 \\
\hline \multicolumn{4}{|l|}{ Tumor site $(n)$} \\
\hline Sinus and nasal cavity & 1 & 1 & 2 \\
\hline Nasopharynx & 0 & 6 & 6 \\
\hline Oropharynx & 2 & 2 & 4 \\
\hline Hypopharynx & 2 & 1 & 3 \\
\hline Larynx & 2 & 1 & 3 \\
\hline \multicolumn{4}{|c|}{ Cisplatin dose, $\mathrm{mg} / \mathrm{body}\left(\mathrm{mg} / \mathrm{m}^{2}\right)$} \\
\hline Median & $111.4(72.24)$ & $138.9(85.6)$ & $128.2(80.4)$ \\
\hline Range & $100-180(61.5-112.5)$ & $66-185(66.7-100)$ & $66-185(66.7-112.5)$ \\
\hline \multicolumn{4}{|c|}{ Total cisplatin dose, $\mathrm{mg} / \mathrm{body}\left(\mathrm{mg} / \mathrm{m}^{2}\right)$} \\
\hline Median & $200-900(123.1-562.5)$ & $145-556(100-300)$ & $145-900(80-562.5)$ \\
\hline Range & $123.1-562.5$ & $80-300$ & $80-562.5$ \\
\hline \multicolumn{4}{|l|}{ Cisplatin infusion cycles } \\
\hline Median & 3.6 & 2.6 & 2.9 \\
\hline Range & $2-5$ & $1-3$ & $1-5$ \\
\hline \multicolumn{4}{|c|}{ Radiation therapy dose (Gy) } \\
\hline Median & 69.4 & 68.7 & 69 \\
\hline Range & $66-70$ & $66-70$ & $66-70$ \\
\hline
\end{tabular}

10 and $12 \mathrm{kHz}(p=0.028,0.039$, respectively, Figure 2). The ototoxicity could only be observed in the ultra-high frequencies. There was minimal or no hearing loss at frequency $\leq 8 \mathrm{kHz}$. Group 2 had a mean age of 61 years and was treated with systemic administration of cisplatin. In this group, patients had significant hearing loss according to the Wilcoxon signed rank test scale, and this loss was observed at

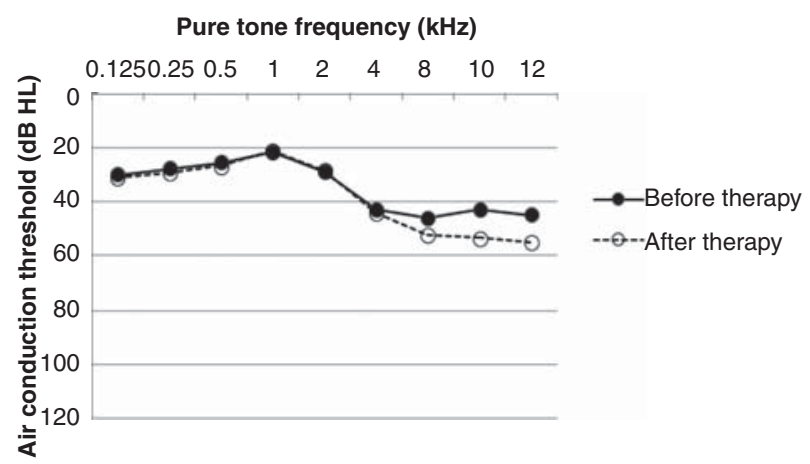

Figure 1. Mean hearing thresholds of all patients before chemotherapy $(\bullet)$ and after chemotherapy $(\bigcirc)$. ultra-high frequencies of 8 and $10 \mathrm{kHz}(p=0.016$, 0.027 , respectively, Figure 3 ). The ototoxicity was only observed at the high and ultra-high frequencies. There was minimal or no hearing loss at frequencies $\leq 4 \mathrm{kHz}$.

\section{Discussion}

Platinum drugs are essential components in chemotherapeutic regimens for HNSCC. The clinical administration of cisplatin is limited by its side effects, including ototoxicity. It is presumed that the basic mechanisms of platinum-induced cytotoxicity in the inner ear are not completely different from those in tumor cells. Cisplatin acts in the cell via many mechanisms, such as DNA damage and the production of reactive oxygen species, which lead to programmed cell death by apoptosis. Cell death can also occur via necrosis when cells are exposed to high concentrations of cisplatin [8]. A factor specifically associated with inner ear damage is drug uptake from the stria vascularis into the cochlear fluids and hair cells. Systemic platinum is trafficked across the 
Pure tone frequencies $(\mathrm{kHz})$

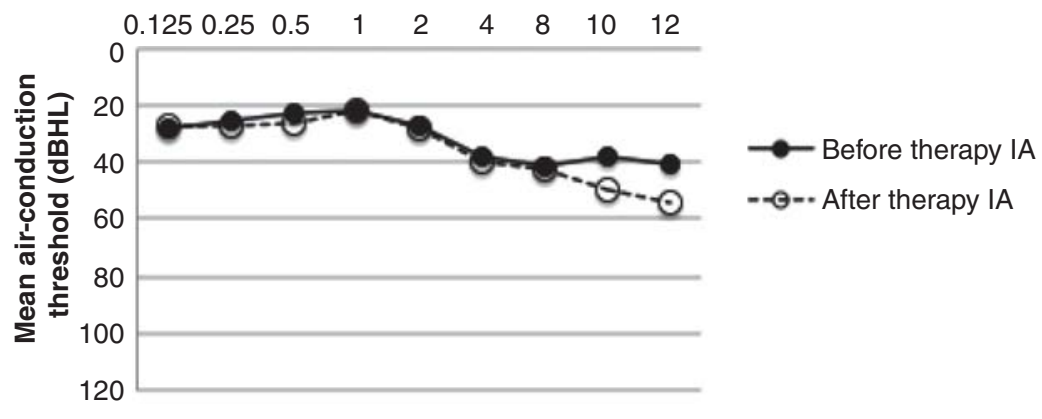

Figure 2. Mean hearing thresholds of intra-arterial high-dose cisplatin chemoradiation with sodium thiosulfate (CRT-IA).

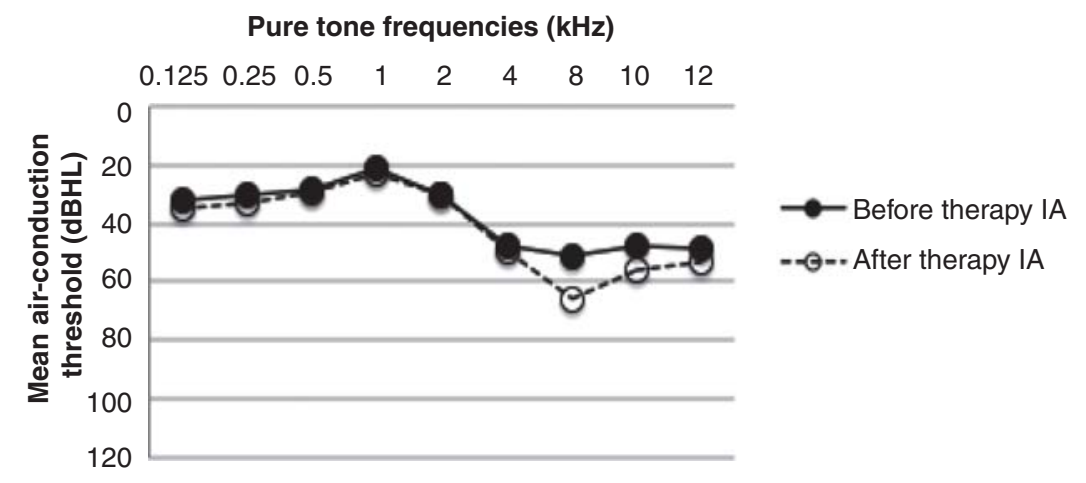

Figure 3. Mean hearing thresholds of intravenous high-dose cisplatin chemoradiation without sodium thiosulfate (CRT-IV).

blood-endolymph barrier and preferentially enters hair cells through their apical membranes [4]. Platinum-induced hearing loss initially occurs at higher frequencies and subsequently affects the lower ones [8]. In the present study, we observed the hearing loss from intravenous cisplatin chemoradiation without STS (CRT-IV) at high and ultra-high frequencies. However, the hearing loss from intraarterial high-dose cisplatin chemoradiation (CRT-IA) with STS was observed only at ultra-high frequencies. The difference between CRT-IA and CRT-IV treatments could be due to STS, the neutralizing agent for cisplatin. STS is a reactive thiol agent clinically used as an antidote to cyanide or nitroprusside poisoning. At high molar excess, STS binds to and inactivates the electrophilic platinum compound in vitro [9]. In CRT-IA treatment, cisplatin is directly infused into the nutrient artery of the tumor. STS is simultaneously infused systemically in the systemic administration of cisplatin. The direct intra-arterial infusion allows the tumor bed to initially receive the full dose of cisplatin before the neutralizing agent and allows the systemic organs to receive the neutralizing agent (Figure 4). It is considered that this regimen prevented the hearing loss from CRT-IA at lower frequencies.
Furthermore, the extent of hearing loss with the Kanazawa regimen was lower than that with RADPLAT. Although previous reports describing the outcomes of clinical trials with RADPLAT did not comment on the incidence and extent of hearing loss due to treatment, significant hearing loss due to RADPLAT was shown in the studies by Madasu et al. [10]. They reported the mean threshold

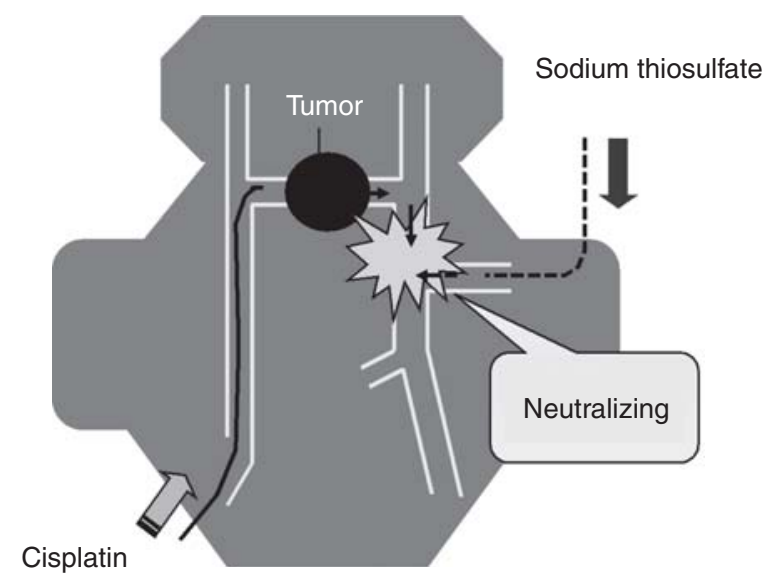

Figure 4. Cisplatin as a neutralizing agent. 
shifts derived from data recorded after RADPLAT. The shifts ranged below $5 \mathrm{~dB}$ at frequencies below $2 \mathrm{kHz}$. However, the noted hearing losses were observed at frequencies above $4 \mathrm{kHz}, 15 \mathrm{~dB}$ at $4 \mathrm{kHz}$ and $23.2 \mathrm{~dB}$ at $8 \mathrm{kHz}$. On the other hand, in our data, the mean thresholds of the AC after CRTIA at frequencies below $8 \mathrm{kHz}$ were almost the same as those before CRT-IA. Zuur et al. also reported hearing loss caused by intra-arterial cisplatin chemoradiation, particularly at ultra-high frequencies [11]. In their study, the mean total threshold shift at PTA AC 8,10 , and $12.5 \mathrm{kHz}$ was $20.4 \mathrm{~dB}$ for CRT-IA. The present study showed that the mean total threshold shift at PTA AC 8, 10, and $12 \mathrm{kHz}$ was only $6.9 \mathrm{~dB}$ for CRT-IA. STS was administered in the cases studied by Madasu et al. and Zuur et al. [10,11]. The relatively lesser extent of hearing deterioration in our regimen may be explained by the use of a lower dose of cisplatin than used in RADPLAT. The incidence and extent of ototoxicity caused by cisplatin are associated with cumulative cisplatin [4]. In the present study, the median dose per infusion of cisplatin was $111 \mathrm{mg}$, less than $80 \mathrm{mg} / \mathrm{m}^{2}$. In contrast, in the cases of Madasu et al. and Zuur et al., who followed the RADPLAT protocol, the dose per infusion of cisplatin was $150 \mathrm{mg} / \mathrm{m}^{2}[10,11]$. The median dose per infusion of cisplatin was $267 \mathrm{mg} / \mathrm{m}^{2}$ in the report by Zuur et al. [11]. The final difference in cumulative cisplatin after therapy between our protocol and RADPLAT was over $600 \mathrm{mg}$. The lower dose of cisplatin appears to have contributed to the smaller extent of ototoxicity.

On the other hand, we detected hearing loss in CRT-IA only at ultra-high frequencies of 10 and $12 \mathrm{kHz}$ in the present study. Cisplatin ototoxicity has been identified to cause hearing loss, beginning at the higher frequencies and, with increasing doses or prolonged treatment, progressively extending to lower frequencies [12]. So typical audiologic assessment (frequencies of $0.125,0.25,0.5,1,2,4,8 \mathrm{kHz}$ ) could not detect hearing loss in patients who received CRTIA. The results of the present study show the possibility that testing ultra-high frequencies enables us to detect early ototoxicity by cisplatin. Early detection of ototoxicity would be helpful in protecting against ototoxicity and treating patients with consideration of their quality of life.

A major toxic effect of cisplatin nephrotoxicity may be avoided with adequate hydration and diuresis; the major hematological toxicities may be reduced with administration of bone marrow growth factors. However, there appears to be no effective medical treatment for limiting or preventing ototoxicity. Therefore, it is very important to prevent or reduce the cisplatin-associated ototoxicity without decreasing tumor cytotoxicity. In the present study, we showed reduced cisplatin ototoxicity resulting from our intraarterial infusion protocol using STS, the neutralizing agent for cisplatin.

\section{Conclusion}

The hearing loss from CRT-IA was only observed at ultra-high frequencies. On the other hand, a wider range of frequency-associated hearing loss was observed with CRT-IV. This suggests that the intra-arterial infusion protocol presents with a relatively lesser extent of cisplatin ototoxicity. This difference between CRT-IA and CRT-IV could be caused by STS, the neutralizing agent for cisplatin. The results of this study also suggest that early detection of ototoxicity is possible by detecting early hearing loss at ultra-high frequencies.

Declaration of interest: The authors report no conflicts of interest. The authors alone are responsible for the content and writing of the paper.

\section{References}

[1] Parkin DM, Bray F, Ferlay J, Pisani P. Estimating the world cancer burden: Globocan 2000. Int J Cancer 2001;94:153-6.

[2] Bernier J, Domenge C, Ozsahin M, Matuszewska K, Lefebvre JL, Greiner RH, et al. Postoperative irradiation with or without concomitant chemotherapy for locally advanced head and neck cancer. N Engl J Med 2004;350: 1945-52.

[3] Cooper JS, Pajak TF, Forastiere AA, Jacobs J, Campbell BH, Saxman SB, et al. Postoperative concurrent radiotherapy and chemotherapy for high-risk squamous-cell carcinoma of the head and neck. N Engl J Med 2004;350:1937-44.

[4] Langer T, am Zehnhoff-Dinnesen A, Radtke S, Meitert J, Zolk O. Understanding platinum-induced ototoxicity. Trends Pharmacol Sci 2013;34:458-69.

[5] Robbins KT, Vicario D, Seagren S, Weisman R, Pellitteri P, Kerber C, et al. A targeted supradose cisplatin chemoradiation protocol for advanced head and neck cancer. Am J Surg 1994;168:419-22.

[6] Kerber CW, Wong WH, Howell SB, Hanchett K, Robbins KT. An organ-preserving selective arterial chemotherapy strategy for head and neck cancer. AJNR Am J Neuroradiol 1998;19:935-41.

[7] Yoshizaki T, Wakisaka N, Murono S, Kondo S, Shimizu Y, Takanaka $\mathrm{T}$, et al. Intra-arterial chemotherapy less intensive than RADPLAT with concurrent radiotherapy for resectable advanced head and neck squamous cell carcinoma: a prospective study. Ann Otol Rhinol Laryngol 2007;116: 754-61.

[8] Goncalves MS, Silveira AF, Teixeira AR, Hyppolito MA. Mechanisms of cisplatin ototoxicity: theoretical review. J Laryngol Otol 2013;127:536-41.

[9] Harned TM, Kalous O, Neuwelt A, Loera J, Ji L, Iovine P, et al. Sodium thiosulfate administered six hours after cisplatin does not compromise antineuroblastoma activity. Clin Cancer Res 2008;14:533-40. 
[10] Madasu R, Ruckenstein MJ, Leake F, Steere E, Robbins KT. Ototoxic effects of supradose cisplatin with sodium thiosulfate neutralization in patients with head and neck cancer. Arch Otolaryngol Head Neck Surg 1997;123: 978-81.

[11] Zuur CL, Simis YJ, Lansdaal PE, Hart AA, Schornagel JH, Dreschler WA, et al. Ototoxicity in a randomized phase III trial of intra-arterial compared with intravenous cisplatin chemoradiation in patients with locally advanced head and neck cancer. J Clin Oncol 2007;25:3759-65.

[12] Aguilar-Markulis NV, Beckley S, Priore R, Mettlin C. Auditory toxicity effects of long-term cis-dichlorodiammineplatinum II therapy in genitourinary cancer patients. J Surg Oncol 1981;16:111-23. 